\title{
Consumers' Intention to Purchase Electric Vehicles: Influences of User Attitude and Perception
}

\author{
Zulfiqar Ali Lashari $^{1}{ }^{1}$, Joonho Ko ${ }^{1, *}$ and Junseok Jang ${ }^{2}$ \\ 1 Graduate School of Urban Studies, Hanyang University, Seoul 04763, Korea; lashari@hanyang.ac.kr \\ 2 Transportation and Construction Bureau Bus Operation Division, Daejeon Metropolitan City, \\ Daejeon 35242, Korea; junseokjang@korea.kr \\ * Correspondence: jko@hanyang.ac.kr
}

Citation: Lashari, Z.A.; Ko, J.; Jang, J. Consumers' Intention to Purchase Electric Vehicles: Influences of User Attitude and Perception. Sustainability 2021, 13, 6778. https:// doi.org/10.3390/su13126778

Academic Editor: Tomio Miwa

Received: 11 May 2021

Accepted: 11 June 2021

Published: 15 June 2021

Publisher's Note: MDPI stays neutral with regard to jurisdictional claims in published maps and institutional affiliations.

Copyright: (c) 2021 by the authors. Licensee MDPI, Basel, Switzerland. This article is an open access article distributed under the terms and conditions of the Creative Commons Attribution (CC BY) license (https:/ / creativecommons.org/licenses/by/ $4.0 /)$.

\begin{abstract}
Electric vehicles (EVs) have been developed as an efficient solution to reduce automobile emissions. To ensure the effective diffusion of EVs in current transport systems, it is vital to understand the factors affecting consumers' intentions to purchase EVs. To provide insights for this understanding, this study aims to investigate such factors with a particular focus on users' attitudes and perceptions. A questionnaire survey was conducted in September 2019 among potential consumers in the major cities of South Korea. A total of 1500 valid survey responses were obtained, and investigations using binary logistic regression and regression tree were conducted for an empirical analysis. The results showed that among attitudinal attributes, environmental and economic perceptions concerning EV use were the strongest predictors for an EV purchase. In addition, technological concerns were found to have negative impacts on EV purchase intentions. The findings of this study could provide reasonable guidelines for establishing marketing strategies and serve as a reference for EV stakeholders to improve the applicability of current policies regarding EV adoption.
\end{abstract}

Keywords: electric vehicles; tree regression; purchase intention; survey

\section{Introduction}

The transportation sector is a major contributor to global carbon dioxide $\left(\mathrm{CO}_{2}\right)$ emissions, and three-quarters of these emissions are generated by road transport [1]. Consequently, growing concerns about the environmental impact of current road transportation systems have accelerated the adoption of clean, energy-efficient and environmentally friendly alternatives that can reduce the carbon footprint [2]. In this context, electric vehicles (EVs) are one of the most commonly considered alternatives [3,4]. EVs have several advantages over conventional vehicles. They are environmentally friendly because they emit no greenhouse gases (GHGs) during operation [1]. EVs are more economical in terms of fuel cost owing to their excellent energy efficiency; their maintenance costs are also lower because of the fewer parts they require [5]. Furthermore, EVs tend to be more comfortable as they produce little vibration and noise [6]. Owing to these benefits, EVs have gradually been recognized as promising alternatives to combustion engine vehicles, and therefore, promoting the purchase and use of EVs can potentially have a large positive impact on the environment and energy systems at both the global and local levels [7].

EV adoption is, however, limited by several barriers such as high retail prices due to the lack of economies of scale, underdeveloped charging infrastructure, short driving ranges that are not sufficient to meet consumer expectations, and high battery replacement costs $[8,9]$. To overcome these limitations, financial incentives such as those to reduce purchase costs have been widely adopted by governments in North America, Europe, and Asia [10]. Moreover, many countries have adopted affirmative measures to encourage people to drive EVs by considering the importance of taking necessary actions to combat climate change [11]. In addition, several European countries have developed long-term EV delivery programs. For example, France's goal is to have two million cumulative EVs on 
the road by 2030, while Germany has a target of one million cumulative EVs [12]. These efforts imply that the market predictions of EVs are relatively positive in most developed countries [13].

In the case of South Korea, the national market for EVs is currently growing at a rapid pace, similar to other developed countries [14]. As a part of the Paris Agreement, the government of Korea has fixed and declared a voluntary target to minimize GHG emissions to $37 \%$ from the business-as-usual (BAU) level by 2030. This voluntary target is planned to be accomplished by a $34 \%$ reduction in GHG emissions from the transport sector. The focus of this plan is the transportation system, with an emphasis on public transport, electric cars, and bicycles. In particular, the Korean government has set a target that $20 \%$ of its new vehicles sold will be green and eco-friendly in the near future. Additionally, new policies have been developed to promote EV sales and emphasize the inclusion of more environmentally sustainable transport technology in the country's overall mobility system. However, despite these developments and government support, EVs still cannot attain the desired market level, and the penetration rate of EVs is only less than $2.5 \%$ in Korea [15]. To address this challenge, it is imperative to understand customer preferences and intentions when opting for EVs. Several studies have explored the moderating effects of personal traits such as perceived value, personal innovativeness, and policy instruments such as government support on the relationship between value attributes and the adoption of EVs [16]. The results of these empirical analyses suggest that the influences of user attitudes and perceptions have significant theoretical and practical implications for EV purchase. They can enable a better understanding of the roles of endogenous personal traits in EV adoption and thus boost the adoption of eco-innovation in the energy and transport industry.

Based on these strategic focuses, this study aims to examine the factors that influence the intention of customers who plan to buy cars in the next three years. In particular, this study focuses on the attitude and perception of users. A survey was conducted to obtain sufficient data; a total of 1500 survey responses were collected to study several aspects of user preferences, reasons, and barriers limiting the adoption of EVs by potential consumers. Logistic regression was used as a modeling approach, along with a multidimensional tree regression classification technique. The results of this research can make several contributions. First, this study adds to the growing body of literature dealing with the factors affecting consumer's intentions to purchase an EV. During the literature review as shown later, it was found that previous studies have identified numerous factors such as social image, environmental concerns, economic benefits, and purchasing costs to be important determinants behind consumer's intention to purchase EVs. However, the literature lacks the user's attitude and perception regarding the acceptance of EVs, which can lead to inefficient strategies that fail to expand the market to a wider range of EV customers. Second, the results of this study will help to understand how changes in a set of specific attitude and perceptions variables affecting the decision to purchase EVs. This understanding will provide direct evidence on the relationship between users' personal perceptions and EV purchase intentions, suggesting that policymakers must consider the characteristics of customers in terms of their preferences and intentions to buy EVs. Finally, the diffusion of EVs in the existing mobility systems of cities is still in its initial phases; therefore, more detailed information is required regarding the factors that may affect consumers' intentions to adopt EVs. This additional information on factors affecting consumers' intentions will provide important implications for automotive industries and other concerned stakeholders in designing improved strategies that motivate consumers to purchase EVs.

The remainder of this paper is organized as follows. Previous studies are discussed in Section 2. The proposed models and data are described in Section 3. Section 4 presents the statistical modeling results. Finally, a summary of the study's findings and conclusions is provided in Section 5. 


\section{Literature Review}

Numerous studies have investigated the variables that affect EV acceptance and consumers' purchase intentions. For example, Wu et al., 2019 [17] explored factors affecting the public acceptance of autonomous EVs by using data collected from an online survey in China. Considering the potential environmental benefits of EVs, they evaluated the environmental concerns that affect people's intentions of buying autonomous EVs. The results of their study showed that perceived usefulness, perceived ease of use, and environmental concern have a positive relationship with consumers' intentions to purchase autonomous EVs. In addition, Wang et al., 2018 [18] analyzed the effects of consumer knowledge about EVs, perceived risks, usefulness, and current financial incentives. The results of their study showed that consumer awareness about EVs has a positive effect on perceived usefulness, attitude, and intention to purchase EVs; however, it is negatively related to perceived risks. Further, to identify the interacting factors in the relationship between perceived value and adoption of EVs, Kim et al., 2018 [16] examined the moderating effects of environmental traits and government support on adoption intentions. They identified operational economic benefits and charging risk as the main motivators or hurdles for EV diffusion. Moreover, they found that environmental concerns and financial incentives significantly enhanced the perceived values of adoption intention. Another study by Schuitema et al., 2013 [19] investigated multidimensional benefits based on users' expectations. They found that the decision to adopt EVs in the United Kingdom is significantly influenced by contributory features such as efficiency, practicality, and driving range; hedonic attributes such as driving pleasure; and symbolic characteristics such as driving pride. The economic benefits of EV adoption have also been examined empirically as primary determinants of acceptance intent for EVs [8,20-22].

In addition to the factors mentioned above, existing empirical studies have identified several meaningful determinants. The authors of [23], for instance, identified the factors affecting the purchase behavior of 2302 early EV buyers in the 21 largest metropolitan areas of the United States. Their results revealed that consumers who express an early interest in adopting EVs are typically highly educated, previous owners of conventional hybrids, environmentally sensitive, and have concerns about dependence on foreign oil. To identify the role of social identity variables such as social norms and collective efficacy in predicting the acceptance of EVs, Ref. [24] collected survey data from 601 respondents, including EV experts in Germany. They found that both EV experts and non-experts considered cost-related factors to be more important than social identity variables in EV adoption. Similarly, Ref. [25] emphasized the cost of EV purchase and suggested that cost is an influential variable given that the decline in prices more effectively stimulates the growth of the EV market. The authors of [26] performed a conjoint analysis concerning the preferences of customers for EVs and fuel-cell vehicles on their potential deployment. They conducted a questionnaire survey on two groups: drivers and non-drivers. The results showed that the purchase price of the vehicle and increased charging stations were the most important variables in the choice of vehicles for both groups. The authors of [27] also confirmed that cost is a key element in the preference of EVs for prospective buyers. The authors of [28] surveyed 502 citizens in Beijing and found that subsidy policies have a substantial positive impact on attitude, perceived behavior management, cognitive status, quality understanding, and monetary incentives, whereas subjective norms and non-monetary incentive policies have little effect. Previous studies have suggested that consumers' perceived usefulness, social image, environmental concerns, economic benefits, and purchasing costs to be the key factors behind a consumer's intention to purchase an EV.

This literature review implies that a considerable number of researchers have analyzed the factors influencing the purchase of EVs. In particular, previous studies suggest that user attitude and perception, as well as personal characteristics and vehicle performance, can have strong impacts. However, currently, the number of studies focusing particularly on user attitude and perception is limited. We argue that this limited information can lead to inefficient strategies that fail to expand the market to a wider range of EV customers. 
This is true because the EV market is still immature, and consumers tend to have relatively narrow information and experience about EVs. Further, this study analyzed technological concerns with different questions covering trust or fear towards new technology and overall inconvenience due to unexpected problem occurrences. In this regard, this study is expected to be meaningful because it contributes to the existing literature on EV adoption, with a special emphasis on the impact of consumers' personal attitudes and perceptions using a case study in South Korea, which has an emerging EV market.

\section{Method and Materials}

\subsection{Survey Design}

This study uses data from a survey that seeks consumer responses toward their intention to purchase EVs. This survey was conducted online in September 2019 by hiring the services of a professional company. A total of 1500 respondents from different metropolitan areas and cities in South Korea, including the capital region comprising the Seoul, Incheon, and Gyeonggi provinces, and seven other major cities, were collected, covering different age groups, gender, income levels, and occupations in the sample. It should be noted that to obtain a reliable dataset, only the respondents who intended to purchase a new vehicle within the next three years were allowed to complete the survey. A structured questionnaire was developed to effectively identify extract the following information: (1) respondents' socio-demographics and economic background, (2) information pertaining to their travels and characteristics of their owned vehicles, and (3) their attitude and perception about EVs. Details about the questions asked concerning their attitude and perception of EVs will be explained in the next section.

Table 1 shows the descriptive statistics of the variables measured in the first and second parts of the questionnaire. The statistics showed that $90.4 \%$ of respondents intend to purchase EVs, which may signify that the EV market in Korea will expand rapidly. The shares of males and females were equally distributed in the dataset; this gender balance was planned in the sampling process to avoid any sample biases by controlling the participation of the survey panel. The age distribution shows that approximately $70 \%$ of the respondents were in their $20 \mathrm{~s}$ and $40 \mathrm{~s}$, followed by those in their $50 \mathrm{~s}$ and $60 \mathrm{~s}$. Most of the respondents were self-employed (52.2\%) and office workers (20.1\%), compared to students and others. The high percentage of self-employed respondents in this sample does not represent the actual distribution of employees in Korea. It is known that the self-employed occupy $24.6 \%$ of the total working population in Korea [29]. Over $85 \%$ of respondents owned a car, and $50 \%$ had over 10 years of driving experience. With respect to household income, 35.6\% of respondents had a monthly household income of 4-6 million KRW. In terms of housing type, $70.8 \%$ of the participants lived in apartments, and the rest lived in multi-family $(17.8 \%)$ and single-family houses (11.4\%). Most participants (93.4\%) were from the capital area and major cities of Korea. In terms of car ownership, over $50 \%$ of the surveyed people had only one vehicle in their households.

\subsection{Measurement of User Attitude and Perceptions}

In this section, the approach to measuring users' attitudes and perceptions concerning EVs is discussed. The survey uses a seven-point Likert scale ranging from 1 to 7 ( 1 = strongly disagree, 7 = strongly agree) to measure the responses of participants related to their attitude and perception toward EVs. Users' attitudes and perceptions were measured in terms of the innovativeness of users, their environmental and technological concerns, perceived economic benefits of using EVs along with subsidies on EV purchase, and the user's perception of their social image when using EVs. 
Table 1. Individual attribute statistics of the sample $(n=1500)$.

\begin{tabular}{|c|c|c|c|c|}
\hline Category & Individual Attributes & Variable Description & Frequency & Proportion (\%) \\
\hline \multirow{2}{*}{ Dependent } & \multirow{2}{*}{ Intention to purchase EV } & Yes & 1356 & 90.4 \\
\hline & & No & 144 & 9.6 \\
\hline \multirow{32}{*}{$\begin{array}{l}\text { Socio-demographic } \\
\text { characteristics }\end{array}$} & \multirow{2}{*}{ Gender } & Male & 750 & 50.0 \\
\hline & & Female & 750 & 50.0 \\
\hline & \multirow{5}{*}{ Age } & $20 \mathrm{~s}$ & 300 & 20.0 \\
\hline & & $30 \mathrm{~s}$ & 370 & 24.6 \\
\hline & & $40 \mathrm{~s}$ & 370 & 24.6 \\
\hline & & $50 \mathrm{~s}$ & 300 & 20.0 \\
\hline & & $60 \mathrm{~s}$ & 160 & 10.6 \\
\hline & \multirow{2}{*}{ Car ownership } & Own/Yes & 1289 & 85.9 \\
\hline & & Do not own/No & 211 & 14.1 \\
\hline & \multirow{3}{*}{ Driving experience (years) } & Up to 5 & 342 & 22.8 \\
\hline & & $5-10$ & 195 & 13.0 \\
\hline & & More than 10 & 752 & 50.1 \\
\hline & \multirow{3}{*}{ Family members } & One & 155 & 10.3 \\
\hline & & Two & 306 & 20.4 \\
\hline & & Three and more & 1039 & 69.3 \\
\hline & \multirow{4}{*}{$\begin{array}{l}\text { Household monthly } \\
\text { income (million KRW) }\end{array}$} & Up to 4 & 428 & 28.5 \\
\hline & & $4-6$ & 535 & 35.6 \\
\hline & & $6-8$ & 283 & 18.8 \\
\hline & & Over 8 & 255 & 17.0 \\
\hline & \multirow{3}{*}{ Type of house possession } & Owner & 1051 & 70.1 \\
\hline & & Lease & 290 & 19.3 \\
\hline & & Monthly Rent & 159 & 10.6 \\
\hline & \multirow{3}{*}{ Housing type } & Apartment & 1062 & 70.8 \\
\hline & & Multi-family house & 267 & 17.8 \\
\hline & & Single-family house & 171 & 11.4 \\
\hline & \multirow{4}{*}{ Occupation } & Self-employed & 783 & 52.2 \\
\hline & & Office workers & 301 & 20.1 \\
\hline & & Students & 162 & 10.8 \\
\hline & & Others & 254 & 16.9 \\
\hline & \multirow{3}{*}{ Location } & Capital area $^{\mathrm{a}}$ & 700 & 46.7 \\
\hline & & Major cities ${ }^{b}$ & 700 & 46.7 \\
\hline & & Other cities ${ }^{c}$ & 100 & 6.6 \\
\hline \multirow{13}{*}{$\begin{array}{l}\text { Travel and vehicle } \\
\text { characteristics }\end{array}$} & \multirow{2}{*}{ Number of cars } & Zero and one & 1050 & 70.0 \\
\hline & & Two and more & 450 & 30.0 \\
\hline & \multirow{5}{*}{ Type of cars (engine size) } & & 114 & 7.6 \\
\hline & & Small and mid-sized (1000-2000 cc) & 769 & 51.3 \\
\hline & & Full-sized (>2000 cc) & 221 & 147 \\
\hline & & SUV & $\begin{array}{l}221 \\
185\end{array}$ & $\begin{array}{l}14.7 \\
123\end{array}$ \\
\hline & & & 100 & \\
\hline & \multirow{3}{*}{ Vehicle age (years) } & $1-5$ & 695 & 46.3 \\
\hline & & $6-10$ & 401 & 26.7 \\
\hline & & More than 10 & 193 & 12.8 \\
\hline & \multirow{3}{*}{$\begin{array}{l}\text { Monthly fuel expenditure } \\
\text { (million KRW) }\end{array}$} & Up to 0.3 & 818 & 54.5 \\
\hline & & $0.4-0.6$ & 312 & 20.8 \\
\hline & & More than 0.6 & 159 & 10.6 \\
\hline
\end{tabular}

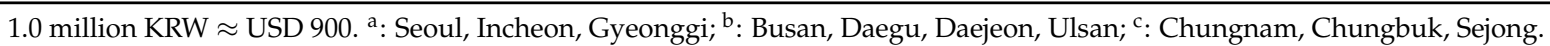

User innovativeness was measured using four questions that asked how much intentions the respondent had to accept new technologies. The questions related to environmental concerns including whether the diffusion of eco-friendly vehicles will help protect 
the environment and reduce air pollution and whether the diffusion is consistent with the current environmental policy. Regarding technological concerns, four questions were considered: (1) fear of new technologies, (2) inconvenience in using EVs, (3) overall safety level for operations, and (4) difficulty in handling situations when unexpected problems (e.g., car break-down, depletion of battery) occur. Perceptions about the economic benefits of EVs were measured by asking the extent to which they agree with the expectations that the purchasing cost of eco-friendly vehicles, their maintenance, and operation costs will be cheaper. In the case of purchase subsidy, the respondents were asked to mark the degree of agreement with these statements: the level of subsidy for purchase will affect the degree of use, taxes, and discounts help me adopt EVs, and financial incentives and related policy support should be performed simultaneously. Finally, social influence or image was measured with two questions by asking how much they agree with the statements: 'I think eco-friendly vehicles are in line with social trends' and 'You will be evaluated as being ahead of the people around you by using eco-friendly vehicles. The details of these measurement approaches, including the questions, are presented in Table 2.

Table 2. Measurement items for users' perceptions and attitude towards EVs.

\begin{tabular}{|c|c|}
\hline Items & Questions \\
\hline \multirow{4}{*}{ Innovativeness } & I challenge new technologies relatively early. \\
\hline & I enjoy experiencing new technology. \\
\hline & I adapt well to new technologies. \\
\hline & I think eco-friendly vehicle-related technologies are innovative. \\
\hline \multirow{4}{*}{$\begin{array}{l}\text { Technological } \\
\text { concerns }\end{array}$} & I have a lot of fear of new technology. \\
\hline & Eco-friendly vehicles will be inconvenient to use because there are many unexpected problems. \\
\hline & Eco-friendly vehicles will not be safe overall. \\
\hline & Eco-friendly vehicles will be difficult to solve when unexpected problems occur. \\
\hline \multirow{3}{*}{ Economic benefit } & The cost of purchasing eco-friendly vehicles will be cheaper than internal combustion engine vehicles. \\
\hline & If you use eco-friendly vehicles, you receive economic benefits such as a reduction in parking fees. \\
\hline & Expenditure on fuel and maintenance will be reduced compared to vehicles with internal combustion engines. \\
\hline \multirow{3}{*}{ Purchase subsidy } & When purchasing eco-friendly vehicles, the level of subsidy for purchase will affect the degree of use. \\
\hline & Economic benefits (taxes and discounts) when purchasing eco-friendly vehicles will affect the degree of use. \\
\hline & Purchase subsidy and economic benefit-related policy support should be performed simultaneously. \\
\hline \multirow{3}{*}{$\begin{array}{l}\text { Environmental } \\
\text { benefits }\end{array}$} & The introduction of eco-friendly vehicles is consistent with the current environmental policy. \\
\hline & Eco-friendly vehicles will emit fewer air pollutants than internal combustion engine vehicles. \\
\hline & The use of an eco-friendly vehicle will help protect the environment. \\
\hline \multirow{2}{*}{$\begin{array}{l}\text { Social } \\
\text { influence/image }\end{array}$} & I think eco-friendly vehicles are in line with social trends \\
\hline & You will be evaluated as being ahead of the people around you by using eco-friendly vehicles. \\
\hline
\end{tabular}

The resulting mean scores for users' attitudes and perceptions of EVs are shown in Figure 1. The figure indicates that the respondents recognize the importance of purchase subsidy and environmental benefits, as shown by their greater scores, 5.48, and 5.46. Moreover, it shows that the score for technological concerns was the lowest (3.94). This may suggest that technological concerns are not a major issue for EV adoption. The survey participants responded that they are to some degree innovative, as suggested by the score of 4.91 (score for neutral $=3.0$ ). 


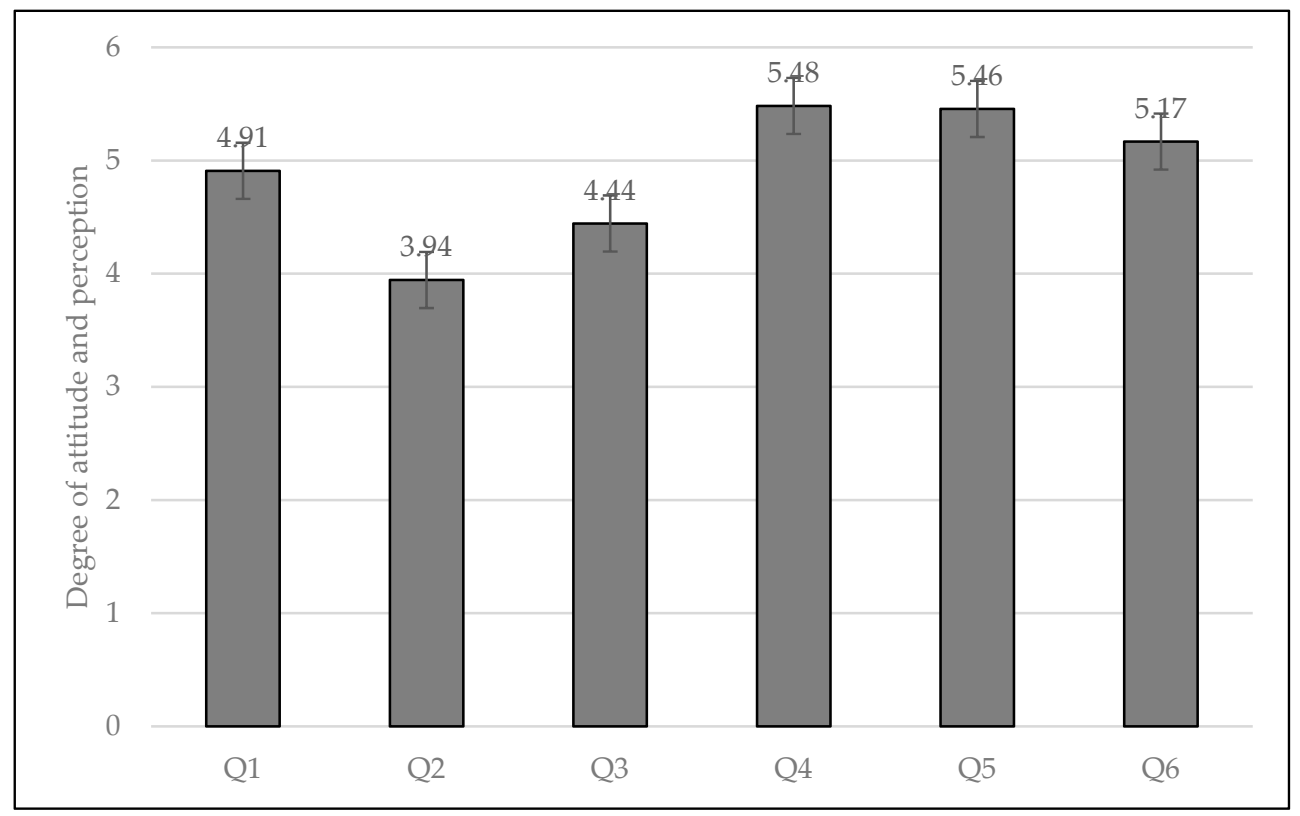

Figure 1. Mean scores of attitude and perception variables. Note: Q1: innovativeness; Q2: technological concerns; Q3: economic benefits; Q4: purchase subsidy; Q5: environmental benefits; and Q6: social influence/image. Error bars represent the $99 \%$ confidence interval for the mean.

\subsection{Models}

In this study, two approaches-regression tree and logistic regression-were used to explore the factors affecting consumers' intention to purchase EVs. The application of both approaches is expected to reveal the factors from various perspectives. The use of these methodologies is intended to demonstrate how a variety of factors impact EV purchase decisions. The classification tree approach is helpful because of its ability to reveal data structures with complex interactions among variables, while not requiring a specific functional form [30]. However, the approach cannot determine the degree to which each variable is statistically meaningful because it is a non-parametric procedure. To overcome this weakness, logistic regression modeling was applied to predict factors affecting consumers' intention to purchase EVs accurately. Studies have shown that the two approaches may be used together to provide a complete explanation of the causal relationships between response and explanatory factors [30,31].

\subsubsection{Regression Tree}

To better understand consumers' intentions to purchase EVs, a multidimensional analysis considering interactions between factors was conducted using the tree-based regression technique. The regression tree method is useful because it can reveal data structures with complex interactions between variables without requiring a particular functional form [30]. An empirical tree is a segmentation of the data generated by applying a series of basic rules in decision tree modeling. Through the repeated splitting process, these models produce a set of homogeneous groups that can be applied for prediction. Chi-squared automatic interaction detection, classification, and regression trees are the most common tree methods [32]. This method is attractive because the resulting trees have a symbolic representation that is simple to interpret [33]. However, the approach cannot determine the degree to which each variable is statistically meaningful because it is a non-parametric procedure. To overcome this weakness, parametric models such as logistic regression are often developed together, enabling analysts to confirm the statistical significance of the identified factors. 


\subsubsection{Binary Logistic Regression}

Logistic regression has been widely used in the analysis of EV purchase literature [34-37]. In this study, a binary logit model was used to identify the factors affecting consumers' intention to purchase EVs. The random utility of a customer is extracted from a single option situation, such as "intention to buy EV" or "do not buy EV." Therefore, the dependent variable is used as a binary variable that takes a value of 1 if the respondent expresses the willingness to buy an EV in the next three years and a value of 0 if the respondent expresses no willingness to buy an EV. The model specifications were as follows:

$$
P=\operatorname{Prob}(Y=1)=\frac{\left(\beta_{0}+\beta_{1} X_{1}+\cdots+\beta_{n} X_{n}\right)}{1+\exp \left(\beta_{0}+\beta_{1} X_{1}+\cdots+\beta_{n} X_{n}\right)}
$$

where $P$ represents the probability of adopting EVs and $Y$ is the dependent variable representing the EV ownership status. The symbols $X_{1} \ldots \ldots X_{n}$ are explanatory variables, $\beta_{0}$ is a constant, and $\beta_{1} \ldots . . \beta_{n}$ are regression coefficients that reflect the impact of explanatory variables on $Y$.

\section{Results and Discussion}

First, the regression tree results are presented in Figure 1, which predicts the most homogenous responses of respondents based on their intentions to buy EVs. Second, the results of the binary logistic regression model are presented, illustrating the influence of consumers' personal attitudes and perceptions that affect the decision to purchase EVs.

\subsection{Regression Tree}

The results of the regression tree are shown in Figure 2. For the construction of the tree, two criteria were applied: (1) at least 50 samples in a final node and (2) depth of tree $=3$. The constructed final tree comprises 17 nodes based on the division of the left subtrees, center subtrees, and right subtrees. The tree indicates that among the considered variables, the perceptions about EVs' economic benefits may be used as the top criteria for classifying consumers' intention to purchase EVs. In addition, users' innovativeness, age (20 s), technological concerns, fuel expenses, driving experience, and vehicle age were found to be key variables determining consumers' intentions.

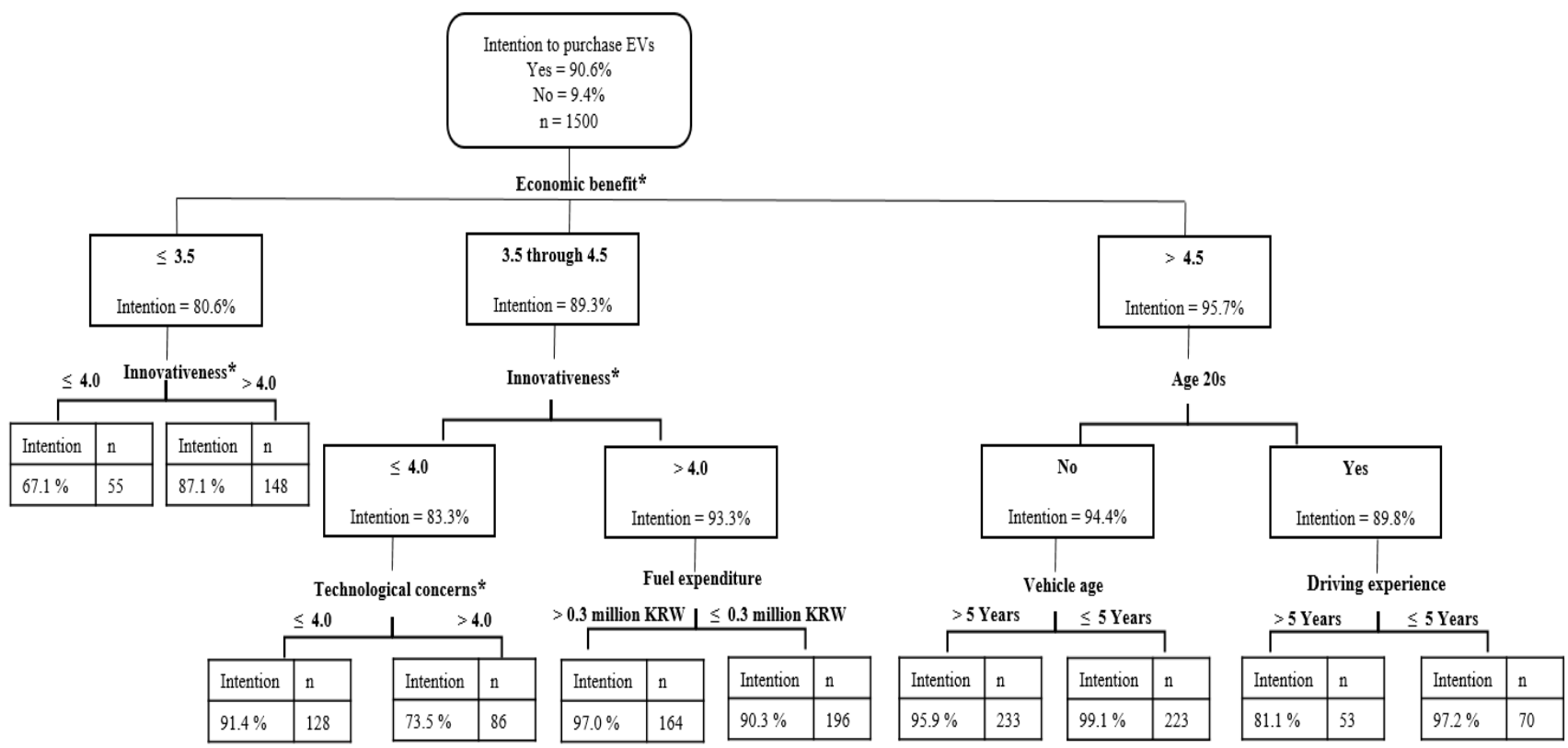

Figure 2. Regression tree for consumers' intention to purchase EVs. ${ }^{*}$ Indicates perception and attitude variables. 
The constructed regression tree with ten terminal nodes, separated by the six factors, clearly indicates that users' perception and attitude variables are the key determinants of the decision to purchase EVs. More specifically, less innovative respondents who weakly perceive the economic benefits of EVs are the least anticipated group of purchasing EVs; among such respondents, only $67.1 \%$ expressed their willingness to buy EVs. Note that for the whole sample, $90.6 \%$ replied that they intend to buy EVs. Conversely, respondents in the $30 \mathrm{~s}$ or older age group who strongly perceive that EVs will bring economic benefits and own a rather new car (vehicle age of $\leq 5$ years) were identified as the most anticipated group of purchasing EVs. Indeed, $99.1 \%$ of the respondents in the group expressed their intention to buy EVs. The constructed tree suggests that technological concerns also exert strong impacts on EV purchase decisions; a higher degree of concern $(>4.0)$ substantially lowers the percentage of respondents who intend to purchase EVs (i.e., from $91.4 \%$ to $73.5 \%$; for this, refer to the third and fourth terminal nodes from the left). Regarding fuel expenditure, the tree implies that respondents who consume more fuel (probably travel longer) are more likely to accept EVs. They may be motivated to save fuel expenditures on EV purchases. In addition, less experienced drivers ( $\leq 5$ years) who belong to the age group of $20 \mathrm{~s}$ and strongly perceive the EVs' economic benefits tend to agree to buy EVs, which is observed in the rightmost two terminal nodes.

\subsection{Binary Logistic Regression}

The results of the binary logistic regression are presented in Table 3. In the regression model, variables were grouped according to their categories to explain the model. The first category includes socio-demographic and economic variables (gender, age, family size, house possession, type of house, area of residence, and household income); the second category comprises attitude variables (users' innovativeness, technological concerns, economic benefits, environmental benefits, and social influence/image), and the third category comprises travel and vehicle characteristics (car ownership, vehicle age, and current vehicle types, travel purpose, driving experience, and monthly fuel cost). However, for brevity, only significant variables are discussed in this section.

The results of the model show that gender is a significant determinant of the decision to purchase EVs. The positive and significant estimated parameter for the male variable indicates that, on average, male respondents are more likely to buy EVs. Concerning age, the young age group, specifically in their $20 \mathrm{~s}$, showed a significantly negative association with purchase intentions. This is unexpected, given that young people are believed to easily accept new technology. However, concerning the purchase price of EVs, which is substantially higher than that of conventional cars, this finding is reasonable. It is highly likely that the income level of young people, particularly in their $20 \mathrm{~s}$, may not be sufficient for the purchase of EVs. Note that these gender and age effects are not always the same. Some previous studies have shown a rather non-significant impact of gender and age variables on EV purchase intention [38,39]. The estimated parameters for the location variable showed that the respondents from the capital area and major cities had a significantly positive intention to buy EVs. These findings can be interpreted as the person from the urban and most developed areas facing relatively higher levels of air pollution due to heavy traffic and, accordingly, may be more aware of the economic and environmental benefits of EVs. The significantly positive coefficient for the variable of housing type (apartment) suggests that people living in apartments are more likely to purchase EVs. This may be because apartment complexes can easily provide parking facilities equipped with chargers because of their sufficient parking supply. Concerning household income, respondents with a household income of up to 4 million KRW showed a significantly positive coefficient value. This implies that lower-income people who are disproportionately burdened by fuel, maintenance, and repair costs of conventional vehicles can be motivated to purchase EVs. 
Table 3. Estimation results of binary logistic regression $(n=1500)$.

\begin{tabular}{|c|c|c|c|}
\hline Category & Variables/Reference Variable & Variable Description & Coefficients \\
\hline & & Constant & $-3.214^{* *}$ \\
\hline \multirow{19}{*}{$\begin{array}{l}\text { Socio-demographic } \\
\text { characteristics }\end{array}$} & $\begin{array}{c}\text { Gender } \\
\text { (Ref. = Female) }\end{array}$ & Male & $0.861^{* * *}$ \\
\hline & \multirow{4}{*}{$\begin{array}{c}\text { Age } \\
\text { (Ref. }=60 \mathrm{~s})\end{array}$} & $20 \mathrm{~s}$ & $-1.164^{* * *}$ \\
\hline & & $30 \mathrm{~s}$ & -0.358 \\
\hline & & $40 \mathrm{~s}$ & -0.615 \\
\hline & & $50 \mathrm{~s}$ & -0.775 \\
\hline & \multirow{2}{*}{$\begin{array}{l}\text { Location } \\
\text { (Ref. = other cities) }\end{array}$} & Capital area & $1.065^{* *}$ \\
\hline & & Major cities & $1.115^{* *}$ \\
\hline & \multirow{2}{*}{$\begin{array}{c}\text { House type } \\
\text { (Ref. = single-family) }\end{array}$} & Apartment & $0.226^{* *}$ \\
\hline & & Multi-family & -0.942 \\
\hline & \multirow{3}{*}{$\begin{array}{l}\text { Monthly household income (million KRW) } \\
\text { (Ref. }=6-8)\end{array}$} & Up to 4 & $0.926^{*}$ \\
\hline & & $4-6$ & 0.385 \\
\hline & & $>8$ & 0.430 \\
\hline & \multirow{3}{*}{$\begin{array}{l}\text { Occupation } \\
\text { (Ref. = others) }\end{array}$} & Self-worker & 0.101 \\
\hline & & Office worker & -0.032 \\
\hline & & Student & 0.853 \\
\hline & \multirow{2}{*}{$\begin{array}{l}\text { Family size } \\
\text { (Ref. = one) }\end{array}$} & Member 2 & -0.003 \\
\hline & & Member 3 and above & -0.403 \\
\hline & \multirow{2}{*}{$\begin{array}{l}\text { House possession } \\
\text { (Ref. = monthly rent) }\end{array}$} & Owner & -0.302 \\
\hline & & Lease & -0.197 \\
\hline \multirow{6}{*}{ Attitude and perceptions } & & Innovativeness & $0.348^{* * *}$ \\
\hline & & Technological concerns & $-0.443^{* * *}$ \\
\hline & & Environmental benefit & $0.489 * * *$ \\
\hline & & Economic benefit & $0.472^{* * *}$ \\
\hline & & Purchase subsidy & -0.095 \\
\hline & & Social influence & 0.068 \\
\hline \multirow{13}{*}{$\begin{array}{l}\text { Travel and vehicle } \\
\text { characteristics }\end{array}$} & $\begin{array}{c}\text { Number of cars } \\
\text { (Ref. = zero and one) }\end{array}$ & Multi cars & $0.499 *$ \\
\hline & \multirow{3}{*}{$\begin{array}{c}\text { Car type } \\
\text { (Ref. = SUV) }\end{array}$} & Mini & -0.389 \\
\hline & & Small \& mid-size & $-0.647^{*}$ \\
\hline & & Full-size & $-0.746^{*}$ \\
\hline & \multirow{2}{*}{$\begin{array}{l}\text { Vehicle age (years) } \\
\quad(\text { Ref. } \geq 10)\end{array}$} & $1-5$ & -0.066 \\
\hline & & $6-10$ & 0.226 \\
\hline & \multirow{2}{*}{$\begin{array}{l}\text { Driving experience (years) } \\
\text { (Ref. }=6-10)\end{array}$} & Up to 5 & 0.231 \\
\hline & & More than 10 & -0.316 \\
\hline & \multirow{3}{*}{$\begin{array}{l}\text { Travel purpose } \\
\text { (Ref. = others) }\end{array}$} & Works and schools & 0.455 \\
\hline & & Business & 0.723 \\
\hline & & Shopping & 0.249 \\
\hline & \multirow{2}{*}{$\begin{array}{l}\text { Monthly fuel expenses (million KRW) } \\
\text { (Ref. } \geq 0.6 \text { ) }\end{array}$} & up to 0.3 & -0.388 \\
\hline & & $0.4-0.6$ & 0.415 \\
\hline & \multicolumn{2}{|c|}{ McFadden Pseudo $R^{2}$} & 0.537 \\
\hline
\end{tabular}

In addition, the estimated model indicates that customers' attitudes and perceptions can have a strong impact on the intention to purchase EVs. In particular, respondents' innovativeness, environmental concerns, and economic benefits showed a positive and statistically significant association with the intention to purchase EVs. As expected, the 
level of technological concerns was found to have a significantly negative relationship with EV purchase, suggesting that regular maintenance and car safety are critical factors for EV adoption by individuals. Meanwhile, the model did not reveal any significant impact on the two variables of purchase subsidy and social influence. In this study, the magnitude of the estimated coefficient for the environmental aspect variable was the largest (0.489) compared to other attitude and perception variables, suggesting that it is the strongest predictor among the six variables. Note that the perception of economic benefits was the most critical factor in the regression tree analysis. This result is generally consistent with the findings of previous studies. For example, [38] reported similar results with the highest value of the coefficient for environmental aspects. Additionally, [16] reported that the economic benefits of EVs have a positive impact on purchase intention. These findings suggest that respondents' perceptions of the government's financial incentives, current environmental policy, and public parking benefits for EVs play vital roles in consumers' intention to purchase EVs.

Finally, the estimated parameters for the vehicle characteristics indicate that respondents who own multiple cars respond positively to EV purchases. This may reflect the fact that EVs are often used as a second car in a household because of their limited driving range. The estimated parameters for the vehicle type variable confirmed that the owners of medium to large vehicles negatively respond to EV purchases, compared to those who own a smaller car. This can be understood by the fact that current EVs in the market are mostly small. Similar findings were also found by $[8,15]$, suggesting that respondents owning full-size cars are less likely to opt for EVs. However, the estimated model also shows that SUV owners have intentions to buy EVs, which is counterintuitive in that EVs in the form of SUVs are rarely available in the market. Further studies are required to explain this situation. EV purchase intentions are expected to greatly change as the EV lineup in the market grows.

Statistical models were developed by applying both regression tree and binary logistic regression based on a binary response variable (intention to purchase $\mathrm{EV}$ or do not purchase EV) and twenty explanatory variables. The two approaches complemented each other and revealed various aspects of the intention to purchase EVs. For example, regression tree analyses revealed that economic benefits can be used as the top criteria for classifying consumers' intention to purchase EVs. In addition, respondents in $30 \mathrm{~s}$ or older age group and vehicle age of $\leq 5$ years were identified as the most predicted group of purchasing EVs. In terms of fuel expenditure, the tree suggested that respondents who use more fuel (so travel for a longer distance) are more likely to purchase EVs. They may be persuaded to purchase EVs for saving fuel expenditure.

The results of the logistics regression further complimented the findings of tree regression with the added information of explanatory variables. Socio-demographic characteristics were found to be significantly associated with intention to purchase EVs. In particular, lower-income respondents are more likely to purchase EVs. This means that lower-income people who are excessively burdened by fuel, maintenance, and repair costs of conventional vehicles can be motivated to purchase EVs. In addition, male respondents have stronger intentions to accept EVs. Regarding age, the young age group, particularly in their $20 \mathrm{~s}$, showed a significantly negative association with purchase intentions.

In addition, the estimated model indicates that customers' attitudes and perceptions can have a strong impact on the intention to purchase EVs. In particular, respondents' innovativeness, environmental concerns, and economic benefits showed a positive and statistically significant association with the intention to purchase EVs. Concerning car ownership, respondents who own multiple cars are more likely to purchase EVs. The estimated parameters for the vehicle type variable confirmed that the owners of medium to large vehicles negatively respond to EV purchases, compared to those who own a smaller car. 


\section{Conclusions}

This study aimed to explore the factors affecting consumers' intentions to purchase EVs, focusing specifically on users' perception and attitude using survey data. Users' perception and attitudinal attributes considered in this study included users' innovativeness, technological concerns, expected environmental and economic benefits, purchase subsidy, and social influence/image. In addition to these attributes, respondents' sociodemographic, economic, and vehicle and travel characteristics were examined. In this study, two approaches-tree regression and binary logistic regression-were used. The random utility of a customer was extracted from a single-option situation, which is the intention to buy EVs. The statistical models successfully produced interpretable outcomes, revealing the influencing factors; thus, they can be used to help analysts reasonably predict a consumer's intention to purchase an EV. There are two major conclusions drawn in this study that are worthy of attention for boosting sales in the EV market and promoting their wide application in transportation systems.

First, this study highlights the importance of consumers' attitudes and perception variables. The results of the logistic regression revealed that among the six variables of attitude and perception, four were statistically significant. In particular, the environmental benefits variable was found to be the strongest predictor of positive attitudes toward EVs. This finding can provide insights to the government and car manufacturers. More specifically, the government can intensify the public perception of EVs by emphasizing their environmental benefits. When planning the expansion of the EV market, EV manufacturers should consider the environmental concerns that their potential customers may have. In addition, the findings provide evidence that the perception of the economic benefits of using EVs has a strong impact on EV purchase intentions. This emphasizes the consensus that it is vital for customers to recognize the advantages of EVs in terms of economic efficiency, such as lower operating costs. This added awareness among consumers will help to form substitute relationships between existing vehicles (conventional vehicles) and EVs. Additionally, consumers' perceptions of government incentives that are aligned with existing environmental policies, as well as measures for lowering the EV operating cost, play a significant role in their decision to purchase EVs.

Second, as reported by several previous studies $[16,26]$, we found that perceived technological concerns have a negative impact on EV purchase intentions. The technological concern variable primarily addressed the concerns of respondents toward EV technology, which is still in its infancy and therefore is more responsible for a safety issue that reduces the probability of consumers purchasing EVs. Consequently, it is imperative to increase consumers' trust in EV technology and boost positive perceptions of EV values to accelerate EV adoption. Prior to making a purchase, consumers go through various processes to assess the overall value of new or innovative products. This value is generally a measure of the overall benefits and risks associated with the intended product. Thus, the government should attempt to advertise the advantages of EVs to alleviate the risks and misunderstandings surrounding EVs; they should also aim to construct more charging stations. Meanwhile, automotive companies should focus on improving their technology, for example, to enhance battery safety and capacity. They may need to offer free test drives to potential consumers to increase their understanding of EVs. Numerous harmonious efforts from governments and car manufacturers are required to educate customers about the economic benefits, comfortable and safe driving, environmental friendliness, and emotional benefits of EVs.

This study provides an interface for the collaboration of city officials and automotive companies to expand EV ownership and increase purchase intentions. This contribution can be strengthened by adding information on factors affecting consumers' intention to purchase EVs, focusing specifically on users' attitudes and perceptions. The evidence provided in this study emphasizes the need to address the characteristics of customers in terms of their intentions and preferences to buy EVs. 
Further studies may improve our understanding of user attitudes and perceptions. For example, the longitudinal observation of behavioral changes of respondents will be useful to draw a more casual relationship between users' personal perceptions and EV purchase intentions. In addition, collecting cross-sectional data covering a wider range of consumers (e.g., from different countries/cities and those with different levels of EV experience) may help in observing the larger picture of divergent EV purchase intentions. Moreover, future researchers can apply different methods of data analysis, such as machine learning and multi-criteria decision-making approaches, to investigate EV purchase intentions and perform comparisons to introduce EVs.

Author Contributions: Conceptualization, Z.A.L. and J.K.; methodology, J.K.; software, Z.A.L.; validation, J.K., Z.A.L. and J.J.; formal analysis, Z.A.L.; investigation, J.K.; resources, J.K.; data curation, J.J.; writing—original draft preparation, Z.A.L.; writing—review and editing, Z.A.L.; visualization, J.J.; supervision, J.K.; project administration, J.K.; funding acquisition, J.K. All authors have read and agreed to the published version of the manuscript.

Funding: This research received no external funding.

Institutional Review Board Statement: Not applicable.

Informed Consent Statement: Not applicable.

Data Availability Statement: Data may be available upon request.

Conflicts of Interest: The authors declare no conflict of interest.

\section{References}

1. McCollum, D.L.; Echeverri, L.G.; Busch, S.; Pachauri, S.; Parkinson, J.R.; Krey, V.; Minx, J.C.; Nilsson, M.; Stevance, A.S.; Riahi, K. Connecting the sustainable development goals by their energy inter-linkages. Environ. Res. Lett. 2018, 13, 033006. [CrossRef]

2. Jansson, J.; Pettersson, T.; Mannberg, A.; Brännlund, R.; Lindgren, U. Adoption of alternative fuel vehicles: Influence from neighbors, family, and coworkers. Transp. Res. Part D Transp. Environ. 2017, 54, 61-73. [CrossRef]

3. Rogelj, J.; Luderer, G.; Pietzcker, R.C.; Kriegler, E.; Schaeffer, M.; Krey, V.; Riahi, K. Energy system transformations for limiting end-of-century warming to below $1.5^{\circ} \mathrm{C}$. Nat. Clim. Chang. 2015, 5, 519-527. [CrossRef]

4. Rockström, J.; Gaffney, O.; Rogelj, J.; Meinshausen, M.; Nakicenovic, N.; Schellnhuber, H.J. A roadmap for rapid decarbonization. Science 2017, 355, 1269-1271. [CrossRef]

5. Schellnhuber, H.J.; Rahmstorf, S.; Winkelmann, R. Why the right climate target was agreed in Paris. Nat. Clim. Chang. 2016, 6, 649-653. [CrossRef]

6. Han, L.; Wang, S.; Zhao, D.; Li, J. The intention to adopt electric vehicles: Driven by functional and non-functional values. Transp. Res. Part A Policy Pract. 2017, 103, 185-197. [CrossRef]

7. Zhuge, C.; Shao, C. Agent-based Modelling of Locating Public Transport Facilities for Conventional and Electric Vehicles. Netw. Spat. Econ. 2018, 18, 875-908. [CrossRef]

8. Hidrue, M.K.; Parsons, G.R.; Kempton, W.; Gardner, M.P. Willingness to pay for electric vehicles and their attributes. Resour. Energy Econ. 2011, 33, 686-705. [CrossRef]

9. Pasaoglu, G.; Fiorello, D.; Martino, A.; Zani, L.; Zubaryeva, A.; Thiel, C. Travel patterns and potential use of electric cars- results from direct survey in six European countries. Technol. Forecast. Soc. Chang. 2014, 87, 51-59. [CrossRef]

10. Lutsey, N. The EV Future-Already Here, Just Not Evenly Distributed Yet? 2015. Available online: http://www.theicct.org/ blogs/staff/ev-future---already-here-just-not-evenly-distributed-yet (accessed on 6 April 2021).

11. Brady, J.; O'Mahony, M. Travel to work in Dublin. The potential impacts of electric vehicles on climate change and urban air quality. Transp. Res. Part D Transp. Environ. 2011, 16, 188-193. [CrossRef]

12. Peters, A.; Dütschke, E. How do consumers perceive electric vehicles? A Comparison of German consumer groups. J. Environ. Policy Plan. 2014, 16, 359-377. [CrossRef]

13. Adnan, N.; Nordin, M.S.; Amini, M.H.; Langove, N. What makes consumers sign up to PHEVs? Predicting Malaysian consumer behavior in adoption of PHEVs. Transp. Res. Part A Policy Pract. 2018, 113, 259-278. [CrossRef]

14. Kim, E.; Heo, E. Key drivers behind the adoption of electric vehicles in Korea: An Analysis of the revealed preferences. Sustainability 2019, 11, 6854. [CrossRef]

15. Hahn, J.S.; Lee, J.H.; Choi, K. Heterogeneous preferences of green vehicles by vehicle size: Analysis of Seoul case. Int. J. Sustain. Transp. 2018, 12, 675-685. [CrossRef]

16. Kim, M.K.; Oh, J.; Park, J.H.; Joo, C. Perceived value and adoption intention for electric vehicles in Korea: Moderating effects of environmental traits and government supports. Energy 2018, 159, 799-809. [CrossRef]

17. Wu, J.; Liao, H.; Wang, J.W.; Chen, T. The role of environmental concern in the public acceptance of autonomous electric vehicles: A survey from China. Transp. Res. Part F Traffic Psychol. Behav. 2019, 60, 37-46. [CrossRef] 
18. Wang, S.; Wang, J.; Li, J.; Wang, J.; Liang, L. Policy implications for promoting the adoption of electric vehicles: Do consumer's knowledge, perceived risk, and financial incentive policy matter? Transp. Res. Part A Policy Pract. 2018, 117, 58-69. [CrossRef]

19. Schuitema, G.; Anable, J.; Skippon, S.; Kinnear, N. The role of instrumental, hedonic, and symbolic attributes in the intention to adopt electric vehicles. Transp. Res. A 2013, 48, 39-49. [CrossRef]

20. Hangman, J.; Ritzen, S.; Stier, J.; Janhanger, S.; Susilo, Y. Total cost of ownership and its potential implications for battery electric vehicle diffusion. Res. Transp. Bus. Manag. 2016, 18, 11-17. [CrossRef]

21. Zhang, X.; Wang, K.; Hao, Y.; Fan, J.L.; Wei, Y.M. The impact of government policy on preference for NEVs: The evidence from China. Energy Policy 2013, 61, 382-393. [CrossRef]

22. Zubaryeva, A.; Thiel, C.; Barbone, E.; Mercier, A. Assessing factors for the identification of potential lead markets for electrified vehicles in Europe: Expert opinion elicitation. Technol. Forecast. Soc. Chang. 2012, 79, 1622-1637. [CrossRef]

23. Carley, S.; Krause, R.M.; Lane, B.W.; Graham, J.D. Intent to purchase a plug-in electric vehicle: A survey of early impressions in the large US cities. Transp. Res. Part D Transp. Environ. 2013, 18, 39-45. [CrossRef]

24. Barth, M.; Jugert, P.; Fritsche, I. Still, underdetected-Social norms and collective efficacy predict the acceptance of electric vehicles in Germany. Transp. Res. Part F Traffic Psychol. Behav. 2016, 37, 64-77. [CrossRef]

25. Cecere, G.; Corrocher, N.; Guerzoni, M. Price or performance? A probabilistic choice analysis of the intention to buy electric vehicles in European countries. Energy Policy 2018, 118, 19-32. [CrossRef]

26. Byun, H.; Shin, J.; Lee, C.Y. Using a discrete choice experiment to predict the penetration possibility of environmentally friendly vehicles. Energy 2018, 144, 312-321. [CrossRef]

27. De Rubens, G.Z.; Noel, L.; Sovacool, B.K. Dismissive and deceptive car dealerships create barriers to electric vehicle adoption at the point of sale. Nat. Energy 2018, 3, 501-507. [CrossRef]

28. Huang, X.; Ge, J. Electric vehicle development in Beijing: An analysis of consumer purchase intention. J. Clean. Prod. 2019, 216, 361-372. [CrossRef]

29. Organization for Economic Cooperation and Development (OECD). 2019. Available online: https:/ / data.oecd.org/emp/selfemployment-rate.htm (accessed on 27 April 2021).

30. Vayssières, M.P.; Plant, R.E.; Allen-Diaz, B.H. Classification trees: An alternative non-parametric approach for predicting species distributions. J. Veg. Sci. 2000, 11, 679-694. [CrossRef]

31. Ko, J.; Lee, S.; Byun, M. Exploring factors associated with commute mode choice: An application of city-level general social survey data. Transp. Policy 2019, 75, 36-46. [CrossRef]

32. Quinlan, J.R. C4.5 Programs for Machine Learning; Morgan Kaufmann: Burlington, MA, USA, 1993.

33. Camdeviren, H.A.; Yazici, A.C.; Akkus, Z.; Bugdayci, R.; Sungur, M.A. Comparison of logistic regression model and classification tree: An application to postpartum depression data. Expert Syst. Appl. 2007, 32, 987-994. [CrossRef]

34. Junquera, B.; Moreno, B.; Alvarez, R. Analyzing consumer attitudes towards electric vehicle purchasing intentions in Spain: Technological limitations and vehicle confidence. Technol. Forecast. Soc. Chang. 2016, 109, 6-14. [CrossRef]

35. Axsen, J.; Bailey, J.H.; Castro, M. Preferences and lifestyle heterogeneity among potential plug-in electric vehicle buyers. Energy Econ. 2015, 50, 190-201. [CrossRef]

36. Zhang, Y.; Yu, Y.; Zou, B. Analyzing public awareness and acceptance of alternative fuel vehicles in China: The case of EV. Energy Policy 2011, 39, 7015-7024. [CrossRef]

37. Brownstone, D.; Bunch, D.S.; Train, K. Joint mixed logit models of stated and revealed preferences for alternative-fuel vehicles. Transp. Res. Part B 2000, 34, 315-338. [CrossRef]

38. Darup, A.S.; Guile, M.; Piulachs, X. Consumer preferences for electric vehicles in Germany. Int. J. Transp. Econ. 2018, 45, 97-122.

39. Degirmenci, K.; Breitner, M.H. Consumer purchase intentions for electric vehicles: Is green more important than price and range? Transp. Res. Part D Transp. Environ. 2017, 51, 250-260. [CrossRef] 